\title{
27 \\ REFLECTION ON DEVELOPMENT TECHNIQUES USING THE PSYCHOLOGY LITERATURE: Over Two Decades of Bias and Conceptual Blocks
}

\author{
Carl Adams \\ University of Portsmouth \\ David E. Avison \\ ESSEC Business School
}

\begin{abstract}
Analysis and development techniques have played an important role in information systems, providing support for developers in structuring and directing tasks. They also provide cognitive support in collecting, collating, analyzing, and representing information about system requirements and attributes. However, by developing previous work further, in particular by classifying techniques into six generic types and transcribing these onto problem/solution space diagrams, this paper argues that by directing tasks and dictating what and how information is collected and represented, techniques can bias developers' understanding of system requirements and attributes.

The 1984 IFIPWG8.2 conference showed how IS can be informed by literature in our foundation disciplines. By drawing on the psychology literature to develop a classification of techniques, this paper shows some of the potential biases inherent in techniques. The classification is applied to many techniques which have contributed to development activity. Through an understanding of the conceptual blocks embedded in them, the paper hopes to inform practice about the selection and mixing of development techniques. More generally, the paper suggests a reexamination of our assumptions when undertaking IS development.

The techniques that limit problem and solution scope most and also provide the most cognitive and conceptual biases are the more formal, objective ones, and we recommend that less formal techniques are also used in practice. Parallels can be drawn with the movement encouraging the use of qualitative research approaches in IS research inspired by the 1984 conference. Research methods and techniques also provide support in the form of directed tasks, activities, guidance on data collection, analysis, and representation. Drawing
\end{abstract}


on this parallel, it could be argued that quantitative, formal research approaches may introduce more conceptual biases than less formal qualitative, approaches, and that the latter should be used instead of, or at least alongside, quantitative approaches.

\section{INTRODUCTION}

Coincidently, around 20 years before the 1984 conference, another landmark event covering the use of computer applications took place in Manchester: the National Computing Centre (NCC) in the UK was formed with a mission to provide UK businesses and organizations with an understanding of how "to enable effective use of information technology" (NCC 2001). The NCC started as a UK government organization to collect and disseminate best practice in computing among its members and businesses. Part of this best practice covered the use of development methods and techniques, in particular by advocating the systems development life cycle or the waterfall model.

The best practice techniques included flow charts, decision tables, structure charts, functional charts, flow diagrams, physical layout charts, grid charts, string diagrams, relationship charts, and a variety of lists and formal documents and forms that systems analysts could use to help capture and represent system attributes. These techniques were the mainstay of traditional systems analysis as covered in many works at that time (Condon and 1974; Couger and Knapp 1974; Daniels and Yeates 1971; FitzGerald 1981; Gane 1979; Kindred 1980; Lee 1979, 1984; Lott 1971; Senn 1989; Wetherbe 1979; Yeates 1973). Many of these development techniques had some diagrammatic attributes as "it is usually easier and more intelligible to record identified procedures in diagrammatic rather than in narrative form" (NCC 1978, p. 116).

Techniques have evolved, and this evolution has similarities with other evolutionary processes. Many of the newer techniques were based on the earlier traditional techniques, bringing out the good practices which seemed most appropriate to address the current development environment of the time. However, sometimes newer techniques are little more than renaming ofolder reincarnations. Other techniques have evolved into something substantially different as the environment focus changes and best practice develops to address that. Some even claim to be completely new varieties. However, even new breeds usually have characteristics that share some visual or process attributes. For instance, the early flow charts and flow diagrams identified as good practice by the NCC have influenced the design of data flow diagrams.

These development techniques, and their reincarnations, have been very useful to analysts and developers over the decades: they provide structure, direct tasks, and provide cognitive tools with which systems analysts and developers can collect, collate, analyze, and represent information about system requirements and attributes. These techniques are usually seen in a positive light.

There is significant published research about the potential negative aspects of using methodologies and tools (along with that discussing their potential 
benefits). Techniques, on the other hand, are seen largely as benign, very often as simple aids to help carry out a task and are used in many methodologies. They might be seen as supporting the collection, collation, analysis, representation or communication of information about system requirements and attributes (or a combination of these) (Adams and Avison 2003, p. 203).

Techniques are generally seen as providing neutral support for developers, enabling them to learn about system requirements and deal with the many challenges of development. However, as Adams and Avison (2003) show, the leading processes and framing attributes of techniques can blinker systems analysts' understanding of system requirements and attributes: "Techniques may provide barriers to problem cognition rather than enlighten, and visual and linguistic influences may blinker perception in one direction" (p. 217).

Each development technique has its own unique set of characteristics distinguishing it from other techniques. Adams and Avison examined about 80 techniques and produced a two-dimensional classification based on visual/ language and paradigm/process influences.

By classifying the characteristics of techniques, [we] indicate how different types of technique are likely to influence problem cognition, and in doing so [have] tried to map the framing effect of techniques. In truth, the discussion of these framing effects has shown that they are complex and interwoven. However, there are two continua that are striking. These are the degree of openness of the approach and the degree to which the technique is rule based. Our major classification places techniques, therefore, into one of four quadrants: prescriptive/ closed; prescriptive/open; non-prescriptive/closed; and non-prescriptive/open....It should be a concern to information systems developers that in our classification of over 80 techniques, over three-quarters are found in the closed rather than open paradigm, suggesting that the vast majority of techniques used in systems work have limited vision. Further, the majority are also prescriptive, limiting perception by restricting the user to a set of rules that should not be transgressed. When they are supported by tools, these rules may be enforced on their users. Even when no tools are in use, these rules are likely to be enforced as "standards" and transgressing them seen as not acceptable (Adams and Avison 2003, p. 220).

One implication from the earlier work is that techniques may limit the scope of understanding system requirements and attributes. The present paper develops this concept further, drawing on works from psychology, in particular by looking at conceptual blocks. To examine the scope ofunderstanding, a classification of techniques is developed based on attributes that affect the problem/solution space.

The rest of this paper is structured as follows: First, works on conceptual blocks are examined. Then relevant attributes of techniques are identified and used to classify techniques. These groupings are considered in terms of problem and solution spaces. The classification is then considered in terms of conceptual block and biases. The paper concludes with a discussion about how this might inform practice. 
Table 1. Four Main Areas of Conceptual Blocks (Adapted from Adams 1987)

\begin{tabular}{|c|c|}
\hline $\begin{array}{l}\text { Perceptual Blocks } \\
\text { - Seeing what you expect to see- stereo- } \\
\text { typing } \\
\text { - Difficulty in isolating the problem } \\
\text { - Tendency to delimit the problem area too } \\
\text { closely (that is, imposing too many con- } \\
\text { straints on the problem) } \\
\text { - Inability to see the problem from various } \\
\text { viewpoints } \\
\text { - Saturation (for example, disregarding } \\
\text { seemingly unimportant or less visible } \\
\text { aspects) }\end{array}$ & $\begin{array}{l}\text { Cultural and Environmental Blocks } \\
\text { - Cultural blocks could include: } \\
\text { - Taboos } \\
\text { - Seeing fantasy and reflection as a waste } \\
\text { of time } \\
\text { - Seeing reasons, logic, numbers, utility, } \\
\text { practicality as good; and feeling, intui- } \\
\text { tion, qualitative judgments as bad } \\
\text { - Regarding tradition as preferable to change } \\
\text { - Environmental blocks could include: } \\
\text { - Lack of cooperation and trust among } \\
\text { colleagues } \\
\text { - Having an autocratic boss } \\
\text { - Distractions }\end{array}$ \\
\hline $\begin{array}{l}\text { Emotional Blocks } \\
\text { - Fear of taking risks } \\
\text { - No appetite for chaos } \\
\text { - Judging rather than generating ideas } \\
\text { - Inability to incubate ideas } \\
\text { - Lack of challenge and excessive zeal } \\
\text { - Lack of imagination }\end{array}$ & $\begin{array}{l}\text { Intellectual and Expressive Blocks } \\
\text { - Use of appropriate cognitive tools and } \\
\text { problem solving language }\end{array}$ \\
\hline
\end{tabular}

\section{CONCEPTUAL BLOCKS}

One of the key works on cognitive blocks is by Adams (1987), who identified four main types, which are represented in Table 1.

Each of these potential blocks can be applied to technique attributes. For instance, perceptual blocks may occur where a technique dictates activities that delimit the problem area, impose constraints, or represent a problem from a particular viewpoint. Emotional blocks may occur where a technique is prescriptive and limits the generation of new ideas. Cultural and environmental blocks may occur where there are strong paradigms or where there are strong traditional approaches to activity. Intellectual and expressive blocks may occur where the technique uses inappropriate tools to capture or represent system attributes.

Groth and Peters (1999), focusing on creative, innovative, and lateral thinking perspectives, examined barriers to creative problem solving among managers. They identify a long list of perceived barriers to creativity including fear of failure, lack of confidence, environmental factors, fear of success and its consequences, fear of challenge, routines, habits, paradigms, preconceived notions, rules, standards, tunnel sight, internal barriers, structure, socialization, external barriers, money, rebellion, health and energy, mood, attitudes, desire, and time. They grouped the perceived barriers into self-imposed, professional environment, and environmentally imposed categories. Fear of some sort seems to be a predominant barrier. This seems to imply that there will be a natural tendency to use familiar techniques, not to move outside the scope of the technique or the expected practice of the environment. 


\section{CHARACTERISTICS OF TECHNIQUES}

To examine further how techniques may introduce conceptual blocks, we need to examine the different attributes of techniques in greater detail. Adams and Avison (2003) collated a list of technique attributes that may contribute to framing system requirements, including

- Visual attributes, for example, visual representation and structure of technique output

- Linguistic attributes, for example, terminology and language used—not just English language, but also others such as mathematical and diagrammatical

- Genealogy attributes, for example, history of techniques, related techniques

- $\quad$ Process and procedure attributes, for example, description and order of tasks

- People attributes, for example, roles of people involved in tasks

- Goal attributes, for example, aims and focus of techniques

- Paradigm attributes, for example, discourse, taken-for-granted elements, cultural elements

- Biases, for example, particular emphasis, items to consider, items not considered

- Technique or application-specific attributes

Some of these characteristics of techniques are explicit, for instance where a particular visual representation is prescribed. Other characteristics might be less obvious, such as the underlying paradigm. Many of the characteristics are likely to be interwoven, for instance the visual and linguistic attributes might be closely aligned with the genealogy of a technique.

To bring together particular attributes of techniques we draw upon the approach used by Waddington (1977) who discusses natural attributes for grouping items. Waddington describes our basic, or natural, methods of ordering complex systems, the most basic of which relies on identifying simple relationships, hierarchies, patterns, and similarities of characteristics. Humans are good at looking for patterns and structure to understand and interpret complex systems: Humans automatically group attributes of a complex system into simpler constructs. The grouping process itself is a little subjective and different people may naturally group techniques differently. For examining the complex array of differing techniques, the focus was on attributes that may impact problem understanding. Initially, the visual representation, process, and linguistic attributes seemed the most appropriate for examining possible blocks to problem understanding (i.e., by defining problem representation, defining processes and language to describe the problem arena). The grouping process started with examining the visual attributes (i.e., presentation) of techniques bringing together techniques with similar presentation characteristics. Then techniques with similar process attributes were collated. Four main groups emerged, two of them based on visual presentation (diagrams or lists/matrices), and two of them based on process and language, one using problem reducing terms and the other using brainstorming terms. The remaining techniques fell into two further groups one looking at different future scenarios and another dealing specifically with conflict situations. The resulting classifications are 
(1) brainstorming approaches, (2) relationship approaches, (3) scenario approaches, (4) reductionist approaches, (5) matrix approaches, and (6) conflict approaches. The grouping process had a few iterations; for instance, initially the relationship approach was split into two groups, one using more formal presentations than the other. An earlier iteration of classification can be seen in Adams and Avison (2002). This grouping process provides a starting point for examining underlying structures in techniques and attributes that may affect problem and solution scoping for a technique.

\section{REPRESENTING PROBLEM AND SOLUTION SPACES ADDRESSED BY TECHNIQUES}

"The future, it has been suggested, is a combination of the known and the unknowable. The proportion of the latter tends to rise as the time-scale extends" (Rosenhead 1992, p. 194). Techniques may be used to identify likely or desirable futures and reduce these, increasing future possibilities to a manageable level. To represent the scoping of how problems are addressed by a technique we use problem and solution space diagrams, or "trumpet of uncertainty" diagrams (Rosenhead 1992, p. 200). The problem and solution space diagrams look like a trumpet or cone where at the smaller end is the current situation (problem, requirements, or our knowledge of those), and as time progresses the total number of all possible situations expands exponentially, represented by a wide bell shape at the other end. Applying a technique is effectively trying to predict the future situation out of all possible future situations. This is represented in Figure 1. Problem and solution diagrams are then applied to each of the six groups.

The brainstorming approaches (Figure 2) perform similar brainstorming and lateral thinking activities. Representations for brainstorming techniques vary, some containing lists and others diagrams (e.g., a mind map). Brainstorming is often associated with Edward de Bono (1970, 1977), who covered it as one of a set of lateral thinking techniques, although there are earlier claims (e.g., Clark 1958). The problem or solution scope is typically expanded to a wide range of areas, but only considered briefly and sometimes without focus, and is sometimes seen as a scattergun approach. There is usually some further activity in selecting some of these areas for further investigation or analysis. A possible representation of the problem solution space for brainstorming approaches is given in Figure 2.

Relationship approaches (Figure 3) are techniques where diagrams are central. Relationship approaches seem to have defined structures and representational relationships between component parts. Included in this grouping are network diagrams (for example, Bicheno 1994) and cognitive mapping (Eden 1992). The problem or solution scope seems to be limited to that defined by the diagram structures.

Scenario approaches (Figure 4) also have linguistic attributes based around future scenarios. There may be some brainstorming or similar activity to identify what the scenarios could be, then there is a deeper investigation of those. In others examples there are given scenarios to work through. Representation in these approaches can vary from lists of items to diagrams. The problem or solution scope is selectively widened; however, the widened areas are examined in depth. 


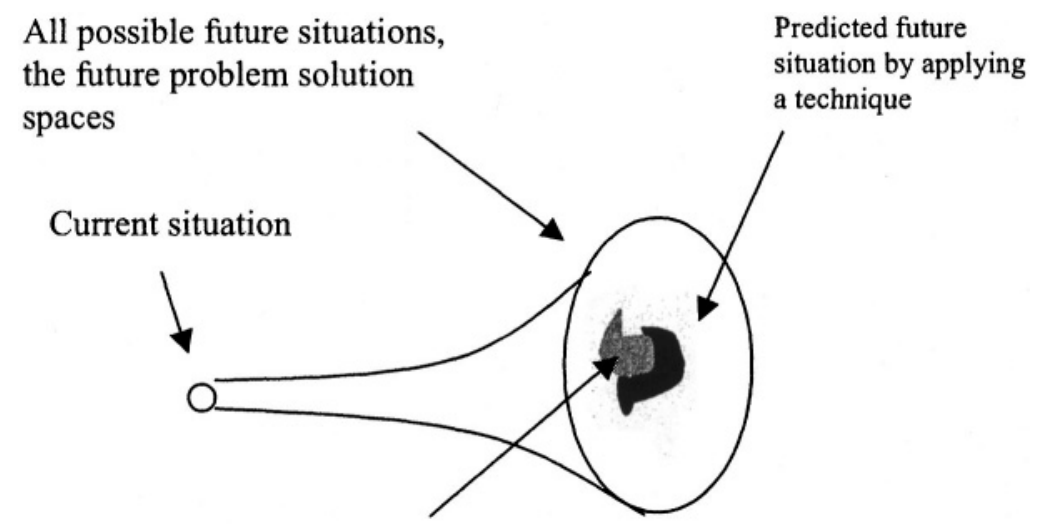

Actual future situation

Figure 1. Representation of Problem and Solution Spaces

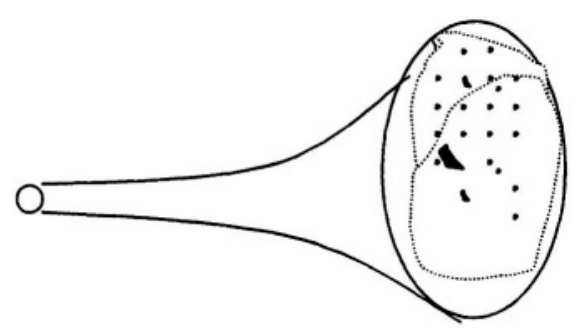

Figure 2. Problem and Solution Spaces for Brainstorming Group

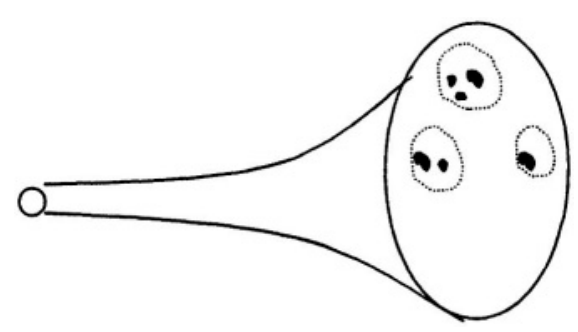

Figure 4. Problem and Solution Spaces for Scenario group

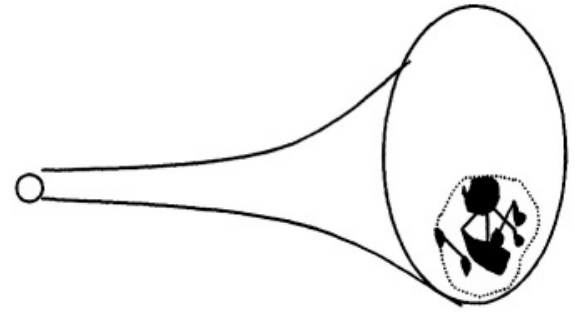

Figure 3. Problem and Solution Spaces for Relationship Group

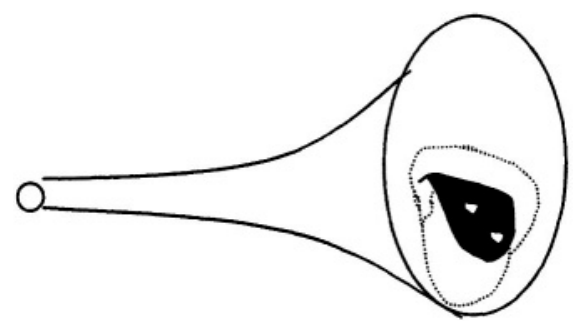

Figure 5. Problem and Solution Spaces for Reductionist group 


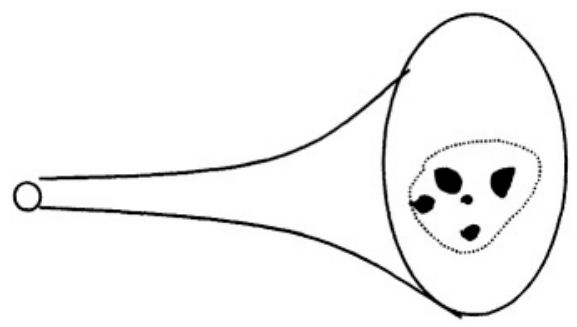

Figure 6. Problem and Solution Spaces for Matrix Group

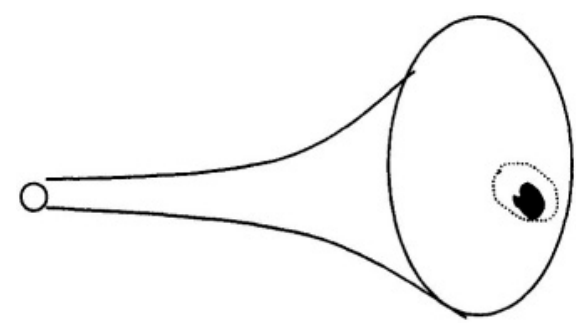

Figure 7. Problem and Solution Spaces for Conflict Group

Reductionist approaches (Figure 5) are techniques that share similar linguistic and terminology attributes, in particular those reducing the problem area into smaller component parts. They also seem to have similar visual attributes based on well-defined structures. The problem or solution scope of these techniques may be limited and directed by the underlying reductionist paradigms (e.g., the solution will materialize by going through the processes defined by the technique).

Matrix approaches (Figure 6) are techniques that present information in lists, matrices or tables. There may be some activity involving the identification of items to include in the lists and activity in identifying attributes of those items. For instance, a list of requirements may be compared or analyzed against a list of factors or constraints. The problem or solution scope may be constrained by the items included within the list or matrix. It will, therefore, be difficult to consider items or issues not on the list.

Conflict approaches (Figure 7) have linguistic and terminology attributes revolving around conflict and conflict resolution. There is usually some activity to identify and represent attributes of the conflict from the main stakeholders' perspective. This would then be used to develop appropriate resolution strategies. The problem solution scope is likely to be constrained to the perceived problem vista from each of the main stakeholders.

The allocation of techniques to particular groups involves a certain amount of subjectivity, and others may put some techniques in another class. In addition, a technique may have attributes placing it in more than one group (e.g., a scenario technique may have brainstorming attributes and a brainstorming technique may have some relationship attributes). In addition, if a technique can be classed in more than one grouping, this will give us more information about the technique. Indeed, some techniques may be a collection of other techniques. The grouping portrays a message or underlying structure about the scoping of a problem and the proposed solution that a technique considers. The problem and solution space figures provide a vista on the scoping of techniques. This provides a basis on which to consider wider cognitive and conceptual blocks. To understand these potential blocks further we will draw on additional literature, again much of it from psychology.

Perceptual blocks may be embedded in techniques that dictate activities and define a particular scope. This would be relevant to relationship and matrix approaches on a 
visual perspective or language and paradigm perspective for reductionist approaches. Emotional blocks may be embedded in techniques which limit scope for innovation, changes to processes and rules, as well as limiting scope for representation. Again, relationship and reductionist approaches fit here. However, on a wider interpretation of the emotional blocks covered by Adams (1987) and closer to the internal barriers, attitudes, habits, and self-imposed attributes discussed by Groth and Peters (1999), people are likely to prefer some techniques and tasks more than others. Some people may like the prescriptive support of reductionist techniques, while others may be more at home with less prescriptive brainstorming activity. Conversely, people will be less at home with less preferred techniques as well as new, untried techniques. From this perspective, emotional blocks will be relevant to all of the categories of techniques. Cultural and environmental blocks may be embedded in techniques that have strong paradigms and rules, such as reductionist approaches. Intellectual and expressive blocks may be embedded in techniques where the tools are inappropriate for capturing, representing, or analyzing system attributes. This could be appropriate to all of the categories of techniques depending on the task context.

For further understanding of potential blocks to understanding, we need to examine other works. The following potential cognitive and conceptual blocks are slightly arbitrarily grouped into three areas: visual representational attributes, language and discourse attributes, and individual orientation attributes.

\section{VISUAL REPRESENTATIONAL ATTRIBUTES}

\subsection{Framing Influences}

We are initially drawn to the framing effect (Tversky and Kahneman 1973, 1974, 1981), which states that different representations of essentially the same situation will result in different decisions, choices, or understanding. Some of the earliest and most influential movements of cognitive psychology, that of the Gestalt psychologists (Gillam 1992; Honderich 1995; Wetheimer 1923), contributed to our understanding of the framing effect.

In Gestalt theory, problem representation rests at the heart of problem solving - the way you look at the problem can affect the way you solve the problem....The Gestalt approach to problem solving has fostered numerous attempts to improve creative problem solving by helping people represent problems in useful ways (Mayer 1996).

The key element here is that the way in which a problem is represented will affect the understanding of the problem. The implication for techniques is that the visual, linguistic, and other representation imposed by a technique will impact understanding on system requirements. The Gestalt movement in cognitive psychology has a (comparatively) long history and has had a big impact on the understanding of problem solving. The movement has spawned various strands of techniques such as lateral thinking and some other creative techniques. Gillam (1992) gives a more current examination of Gestalt theorists and works, particularly in the area of perceptual 
grouping, that is, how people understand and group items. Gillam shows that perceptual coherence (that is, grouping) is not the outcome of a single process (as originally proposed by Gestalt theory) but may be best regarded as a domain of perception (that is, the grouping process is likely to be more complex, influenced by context and other aspects).

\subsection{Category Inclusion}

A prescriptive structure is likely to exert influence on problem cognition. For instance, hierarchy and tree structures are likely to exert some influence on problem cognition by binding attributes together (for example, on the same part of a tree structure) and limiting items to the confines ofthe imposed structure. In cognitive psychology this is known as category inclusion (Anderson and Bower 1973). "One enduring principle of rational inference is category inclusion: categories inherit the properties of their superordinates" (Sloman 1998). The implication is that techniques dictating hierarchical structures will force a (self-perpetuating) category inclusion bias. The reverse is also likely to be true: an element in one branch of a hierarchical structure will automatically have different properties to an element in another branch of the hierarchical structure. For instance, take a functional breakdown of an organization (such as that described in Yourdon and Constantine 1979). One might conclude from category inclusion that a task in an accounting department will always be different to a task in a personnel department, which clearly may not be the case as both departments will have some similar tasks, such as ordering the stationary.

However, this category inclusion is not universally the case. As Sloman (1998) shows us, the process is likely to be more complex. The initial premise surrounding a situation is likely to be related to the underlying paradigm. Dictating a hierarchical structure in itself may not result in category inclusion biases. However, coupled with an underlying closed paradigm, it may more likely result in category inclusion biases. Along the same theme are proximity influences and biases. The understanding of items can be influenced by the characteristics of other items represented in close proximity.

\subsection{Order Influences}

Perceptual processing is profoundly influenced by the sequence in which the information is presented and the relational constructs of information (Mulligan 1999). The order and number of items in a list will influence how people understand (and recall) items and how people categorize them. The initial placing of information items, either in lists or diagrams, will affect understanding of the importance, location and relationship of those items.

\section{LANGUAGE AND DISCOURSE ATTRIBUTES}

\subsection{Discourse Influences}

The discourse and language used to describe a problem is likely to play a role in problem understanding. Adams (1987) discusses various types of languages of thought 
used in problem representing and solving. People can view problems using mathematical symbols and notation, drawings, charts, pictures, and a variety of natural verbal language constructs such as analogies and scenarios. Further, people switch consciously and unconsciously between different modes of thought using the different languages of thought. The information systems development environment is awash with technical jargon and language constructs. In addition, different application areas have their own set of jargon and specific language. Individual techniques have their own peculiar discourse consisting of particular language, jargon, and taken-for-granted constructs, all of which may exert influence. For instance, the initial discourse used affects understanding of a problem situation, particularly in resolving ambiguities (Martin et al. 1999) by setting the context with which to consider the situation.

The initial discourse surrounding requirement identification may be providing leading questions and processes. In addition, cognitive psychology literature indicates that there will be a different weight attached to normative than to descriptive representations and results of techniques. The basis for this is the understanding/ acceptance principle, which states that "the deeper the understanding of a normative principle, the greater the tendency to respond in accordance with it" (Stanovich and West 1999).

Language aspects highlight another set of possible influences, that of communication between different groups of people (such as between analysts and users). Differences of perspective between different groups of people in the development process has been discussed within the IS field under the heading of softer aspects or as the organizational or people issues (for example, Checkland 1981; Lederer and Nath 1991; Sauer 1993). Identifying differences and inconsistencies can be classed as a useful task in identifying and dealing with requirements (Gabbay and Hunter 1991). From cognitive psychology there are also other considerations. Teigen's (1988) work on the language of uncertainty shows that there is often more than the literal meaning implied in the use of a term, such as contextual and relational information or some underlying other message. The use of language is very complex. The implications are that even if a technique prescribes unambiguous language and constructs, there may well be considerable ambiguity when it is used.

\subsection{Goal Influences}

Goal or aim aspects also profoundly influence problem understanding by providing direction and focus for knowledge compilation (Anderson 1987). Goals influence the strategies that people undertake to acquire information and solve problems. Further, when there is a lack of clear goals, people are likely to take support from a particular learning strategy, which will typically be prescribed by the technique.

The role of general methods in learning varies with both the specificity of the problem solver's goal and the systematicity of the strategies used for testing hypothesis about rules. In the absence of a specific goal people are more likely to use a rule-induced learning strategy, whereas provision of a specific goal fosters use of difference reduction, which tends to be a non-rule-induction strategy (Vollmeyer et al. 1996). 
The implications are that techniques with clear task goals will impact the focus and form of information collection (for example, what information is required and where it comes from, along with what information is not deemed relevant) and how the information is to be processed. Further, if there are no clear goals, then people are likely to rely more heavily on the learning method prescribed by the technique.

\section{INDIVIDUAL ORIENTATION ATTRIBUTES}

Some of the individual orientation attributes are similar to the emotional blocks identified earlier.

\subsection{Preference Influences}

There are also likely to be individual preferences, and corresponding biases, for some techniques or specific tasks within techniques. As Puccio (1999) suggests, "the creative problem solving process involves a series of distinct mental operations," that is, in collecting information, defining problems, generating ideas, and developing solutions, people will express different degrees of preference for these various operations. In the information systems domain, Couger (1995) has noted similar preferences: "It is not surprising that technical people are predisposed towards the use of analytical techniques and behaviorally orientated people towards the intuitive techniques."

In addition, there may be some biases between group and individual tasks, a point taken up by Poole (1990), who notes that group interaction on such tasks is likely to be complex with many influences. The theme is also taken up by Kerr et al. (1996), who investigated whether individual activities are better than group activities (that is, have less errors or less bias), but their findings are inconclusive.

the relative magnitude of individual and group bias depends upon several factors, including group size, initial individual judgement, the magnitude of bias among individuals, the type of bias, and most of all, the group-judgment process....It is concluded that there can be no simple answer to the question "which are more biased, individuals or groups?" (Kerr et al. 1996).

To address the potential individual or group biases, many authors suggesting techniques recommend some consideration of the make-up of the different groups using them (for example, Bicheno 1994; Couger et al. 1993), although they give limited practical guidance on doing so.

\subsection{Functional Fixedness}

The Gestalt psychologists also indicate a potentially strong influence on problem understanding, that of functional fixedness "prior experience can have negative effects in certain new problem-solving situations...the idea that the reproductive application of past habits inhibits problem solving" (Mayer 1996). The implication is that habits learned using previous techniques would bias the application of new techniques. This 
is a particular concern in view of the evolution of techniques over the last few decades, and implies that new techniques will have embedded biases as will analysts using a new technique, who will be biased in some way by the habits learned in previously used techniques.

\section{APPLICATION}

As the discussion shows, attributes influencing cognition are likely to be complex and involved. There is much potential for biases based on language, ordering of items, leading processes and questions, and a variety of other attributes of techniques. In addition, the earlier discussion on the evolution, use, and adaptation of techniques indicates that there is likely to be considerable variation in applying a technique. However, we can collate the identified potential cognitive blocks and apply them to the different groups of techniques. This provides a picture of likely biases and cognitive and conceptual blocks for each group. For instance, reductionist techniques are likely to dictate many aspects of the development environment including the processes, representation, and even underlying paradigm. Consequently, such techniques are likely to exert cognitive and conceptual blocks in representation, language, and culture or environment. In addition, the lack of flexibility may also increase emotional block. These potential blocks are summarized for each grouping in Table 2.

In the appendix, we categorize around 70 techniques into the six types listed in Table 2. It is suggested that developers might ensure that they use techniques from different categories, even for a similar task, to reduce the risk of cognitive and conceptual biases due to framing and scoping influences. In addition, there are likely to be further influences, such as individual biases toward different types of techniques (or tasks within them), negative versus positive framing, and a range of perceptual blocks. It is interesting to note that reductionist approaches, with prescriptive processes and paradigms, seem to have the highest potential for introducing cognitive blocks and biases, particularly limiting scope within the mindset of the paradigm. The matrix and relationship approaches seem have high potential to limit scope by the lists and diagrams used. The brainstorming and lateral thinking approaches seemed to have the least potential for introducing biases; however, they also provided the least amount of support in collating and representing system attributes. It is interesting to note that the largest groups of techniques in the appendix are the reductionist, relationship, and matrix approaches, which seems to indicate that biases and cognitive blocking is firmly embedded in the analyst tool box.

\section{CONCLUSION}

Regarding implications for research, there is clearly a need to investigate the phenomenon ofblocks and biases in further understanding. Potential fruitful areas could be in mixing techniques to reduce bias and examining biases in practice.

In addition it is interesting to note that there are parallels between research methods and techniques and development techniques: Research methods and techniques also provide researchers with guidance and support to do their research by directing tasks, dicta- 
Table 2. Potential for Cognitive and Conceptual Blocks and Biases

\begin{tabular}{|c|c|c|c|c|c|c|c|}
\hline \multirow[b]{2}{*}{ Group } & \multicolumn{7}{|c|}{ Potential Cognitive and Conceptual Blocks } \\
\hline & 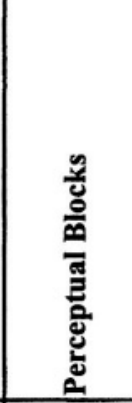 & 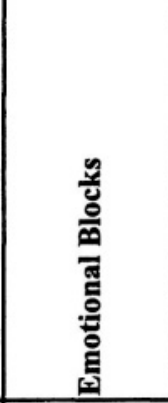 & 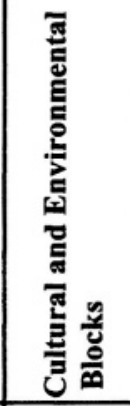 & 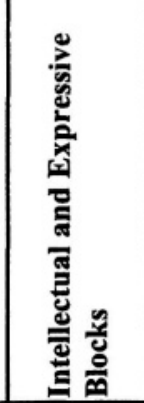 & 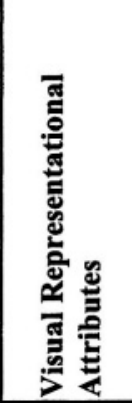 & 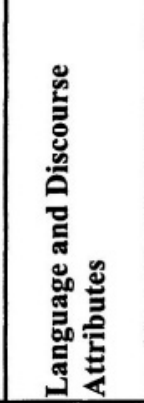 & 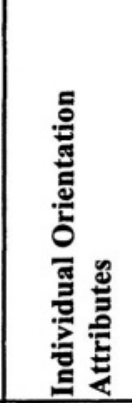 \\
\hline $\begin{array}{l}\text { Brain- } \\
\text { storming }\end{array}$ & Low & $\begin{array}{l}\text { Low/ } \\
\text { Medium } \\
*\end{array}$ & Low & $\begin{array}{l}\text { Low/ } \\
\text { Medium/ } \\
\text { High \# }\end{array}$ & $\begin{array}{l}\text { Low/ } \\
\text { Medium }\end{array}$ & $\begin{array}{l}\text { Low/ } \\
\text { Medium } \\
\# \#\end{array}$ & $\begin{array}{l}\text { Low/ } \\
\text { Medium/ } \\
\text { High ** }\end{array}$ \\
\hline $\begin{array}{l}\text { Relation- } \\
\text { ship }\end{array}$ & High & $\begin{array}{l}\text { High/ } \\
\text { Medium } \\
*\end{array}$ & High & \begin{tabular}{|l|} 
Low/ \\
Medium/ \\
High \# \\
\end{tabular} & High & $\begin{array}{l}\text { Medium/ } \\
\text { High }\end{array}$ & \begin{tabular}{|l} 
Low/ \\
Medium/ \\
High **
\end{tabular} \\
\hline Scenario & $\begin{array}{l}\text { Low- } \\
\text { Medium }\end{array}$ & $\begin{array}{l}\text { Medium } \\
*\end{array}$ & Medium & $\begin{array}{l}\text { Low/ } \\
\text { Medium/ } \\
\text { High \# }\end{array}$ & Medium & Medium & $\begin{array}{l}\text { Low/ } \\
\text { Medium/ } \\
\text { High ** }\end{array}$ \\
\hline $\begin{array}{l}\text { Reduc- } \\
\text { tionist }\end{array}$ & High & $\begin{array}{l}\text { High (lack } \\
\text { of task } \\
\text { flexibility) } \\
*\end{array}$ & $\begin{array}{l}\text { Very } \\
\text { High }\end{array}$ & $\begin{array}{l}\text { Low/ } \\
\text { Medium/ } \\
\text { High \# }\end{array}$ & High & High & $\begin{array}{l}\text { Low/ } \\
\text { Medium/ } \\
\text { High ** }\end{array}$ \\
\hline Matrix & High & $\begin{array}{l}\text { High/ } \\
\text { Medium } \\
*\end{array}$ & High & $\begin{array}{l}\text { Low/ } \\
\text { Medium/ } \\
\text { High \# }\end{array}$ & High & Medium & $\begin{array}{l}\text { Low/ } \\
\text { Medium/ } \\
\text { High ** }\end{array}$ \\
\hline Conflict & $\begin{array}{l}\text { Low- } \\
\text { Medium }\end{array}$ & $\begin{array}{l}\text { Medium } \\
*\end{array}$ & Medium & $\begin{array}{l}\text { Low/ } \\
\text { Medium/ } \\
\text { High \# }\end{array}$ & Medium & $\begin{array}{l}\text { Medium/ } \\
\text { High }\end{array}$ & $\begin{array}{l}\text { Low/ } \\
\text { Medium/ } \\
\text { High ** }\end{array}$ \\
\hline
\end{tabular}

Table key:

*Or Low/Medium/High depending on individual's orientation to tasks

**Depends on individual's orientation to tasks and previous experience \#Applying the most suitable cognitive tools for a given task is context dependent \#\#Could be high if there is a lack of clear goals

ting what information to collect, how to collate and analyze it, and how to represent it. These are likely to have a similar set of biases to the development techniques covered in this paper. There has been a predominance of quantitative objective research approaches just as there is a predominance of objective type development techniques. Our research suggests thatjust as the objective techniques provide the greatest scope for cognitive and conceptual biases and blinkering, so too do the objective research approaches.

For individual research projects, several questions are raised on what biases are introduced when using particular research techniques. Does a particular research 
technique blinker the researcher's perception of the phenomenon being investigated, and if so how? Should the selection of research techniques also include consideration of reducing possible biases in understanding the phenomenon being investigated? For example, in this research, development techniques were initially categorizing under a natural approach indicated by Waddington (1977), however, a different approach to classifying techniques may have highlighted other technique attributes and consequently other possible types of bias.

This paper has contended that techniques influence problem understanding during information systems development. The influences can be considered under certain representational attributes. The psychology literature indicates how these attributes are likely to affect problem understanding. These biases become more prominent when one considers that the results of a technique (that is, diagrams, tables, etc.) may be used by different groups of people than the group that produced them (for example, analysts may produce some charts and tables which will be used by designers) and this is likely to perpetuate such biases throughout the development process.

Techniques have evolved with best practice being developed to address the needs of the business and development environment. However, this paper has shown that techniques are not neutral. They have the potential to introduce bias and cognitive and conceptual blocks, blinkering the analyst's and developer's view of system requirements and attributes. These non-neutral attributes of techniques have also evolved along with the best practice elements.

One of the results of this study is that there is a predominance of techniques with prescriptive representational structures (i.e., matrix approaches and relationship approaches) and/or prescriptive reductionist paradigms, supporting the findings of Adams and Avison (2003), who found a predominance of techniques in the closed objective paradigm. The objective techniques seem to have the biggest potential for reducing problem and solution scope and introducing bias.

There are implications for research, both in topic areas requiring further investigation and in possible biases inherent in research techniques. This is of concern given the predominance of quantitative objective research approaches, just as there is a predominance of objective type development techniques, which seem to offer the greatest scope for cognitive and conceptual biases.

\section{REFERENCES}

Adams, C., and Avison, D. E. "Dangers Inherent in the Use of Techniques: Identifying Framing Influences," IT and People (16:2), 2003, pp. 203-234.

Adams, C., and Avison, D. E. "Macro Analysis of Techniques to Deal with Uncertainty in Information Systems Development: Mapping Representational Framing Influences," in D. Bustard, W. Liu, and R. Sterritt (Eds.), Soft-Ware 2002: Computing in an Imperfect World, Berlin: Springer-Verlag, 2002, pp. 280-299.

Adams, J. Conceptual Blockbusting: A Guide to Better Ideas, Harmondsworth, England: Penguin Books, 1987.

Anderson, J. R. "Skill Acquisition: Compilation of Weak-Method Problem Solutions," Psychological Review (94), 1987, pp. 192-210.

Anderson, J. R., and Bower, G. H. Human Associative Memory, Washington, DC: Winston, 1973. 
Andrew, J., and Moss, T. Reliability andRiskAssessment, Harlow, England: Longman Scientific and Technical, 1993.

Avison, D.E., and Fitzgerald, G. Information Systems Development: Methodologies, Techniques and Tools $\left(3^{\text {rd }}\right.$ ed.), London: McGraw-Hill, 2003.

Batiste, J., and Jung, J. "Requirements, Needs, and Priorities: A Structured Approach for Determining MIS Project Definition," MIS Quarterly (8:4), 1984, pp. 215-227.

Beard, R. Risk Theory, London: Methuen, 1969.

Bennet, P.; Cropper, S.; and Huxham, C. "Modeling Interactive Decision: The Hypergame Focus," in J. Rosenhead (Ed.), Rational Analysis for a Problematic World: Problem Structuring Methods for Complexity, Uncertainty and Conflict, Chichester, England: John Wiley and Sons, 1992, pp. 283-314.

Bicheno, J. The Quality 50: A Guide to Gurus, Tools, Wastes, Techniques and Systems, Buckingham, England: PICSIE Books, 1994.

Camden. Guidelines to the Establishment of Hazards Analysis and Critical Control Points, Technical Manual 19, Camden Food and Drink Association, Glouchestershire, UK, 1987.

Carley, M. Rational Techniques in Policy Analysis, Aldershot, England: Gower Publishing, 1980.

Chapman, C. B. "Model and Situation Specific OR Methods: Risk Engineering Reliability Analysis of LNG Facility," Journal of Operational Research (35:1), 1984, page 27.

Chapman, C. B. "Risk Management," Project Management (18), 1990, p. 5.

Checkland, P. Systems Thinking, Systems Practice, Chichester, England: John Wiley, 1981.

Clark, C. Brainstorming: The Dynamic New Way to Create Successful Ideas, Garden City, NY: Doubleday and Co, Inc., 1958.

Condon, R. J. Data Processing Systems Analysis and Design, Reston, VA: Reston Publishing Company, 1974.

Couger, D. Creative Problem Solving and Opportunity, Danvers, MA: Boyd and Fraser Publishing, 1995.

Couger, D.; Higgins, L.; and McIntyre, S. "(Un)Structured Creativity in Information Systems Organizations," MIS Quarterly (18:4), December 1993, pp. 375-397.

Couger, J. D., and Knapp R. W. (Eds.). System Analysis Techniques, New York: John Wiley \& Sons, 1974.

Daniels, A., and Yeates, D. Basic Training in Systems Analysis ( $2^{\text {nd }}$ ed.), London: Pitman Publishing, 1971.

de Bono, E. Lateral Thinking: A Textbook of Creativity, Harmondsworth, England: Penguin Books Ltd., 1977.

de Bono, E. The Mechanism of Mind, Harmondsworth, England: Penguin Books Ltd., 1969.

de Bono, E. The Use of Lateral Thinking, Harmondsworth, England: Penguin Books Ltd., 1970.

Eden, C. "Using Cognitive Mapping for Strategic Options Development and Analysis (SODA)," in J. Rosenhead (Ed.), Rational Analysis for a Problematic World: Problem Structuring Methods for Complexity, Uncertainty and Conflict, Chichester, England: John Wiley and Sons, 1992, pp. 21-42.

Fagan, M. "Design and Code Inspections to Reduce Errors in Program Development," IBM Systems Journal (15:3), 1976, pp. 182-211.

FitzGerald, J. Fundamentals of Systems Analysis ( $2^{\text {nd }}$ ed.), Chichester, England: John Wiley and Sons, 1981.

Flynn, D. J. Information Systems Requirements: Determination and Analysis, London: McGraw-Hill, 1992.

Fortune, J., and Peters, G. Learning from Failure: The Systems Approach, Chichester England: John Wiley and Wiley, 1995.

Friend, J. K., and Hickling, A. Planning Under Pressure: The Strategic Choice Approach, Oxford: Butterworth-Heinemann, 1997. 
Gabbay, D., and Hunter, A. "Making Inconsistency Respectable: A Logical Framework for Inconsistency Reasoning," Lecture Notes in Artificial Intelligence (535), 1991, London: Imperial College, London, 1991, pp. 19-32.

Gane, C. P. Structured Systems Analysis: Tools and Techniques, London: Prentice-Hall, 1979.

Gajpal, P. P.; Ganesh, L. S.; and Rajendran, C. "Criticality Analysis of Spare Parts Using the Analytic Hierarchy Process," International Journal of Production Economics (35), 1994, pp. 293-297.

Geschka, H. "Creativity Techniques in Germany," Creativity andInnovation Management (5:2), 1996, pp. 87-92.

Gillam, B "The Status of Perceptual Grouping: 70 Years after Wertheimer," Australian Journal of Psychology (44:3), 1992, pp. 157-162.

Grey, S. Practical Risk Assessment for Project Management, Chichester, England: John Wiley and Sons, 1995.

Groth, J., and Peters, J. "What Blocks Creativity? A Managerial Perspective," Creativity and Innovation Management (8:3), 1999, pp. 179-187.

Honderich, T. (Ed.). The Oxford Companion to Philosophy, Oxford: Oxford University Press, 1995.

Howard, N. "Metagame Analysis," in J. Rosenhead (Ed.), Rational Analysis for a Problematic World: Problem Structuring Methods for Complexity, Uncertainty and Conflict. Chichester, England: John Wiley and Sons, 1992, pp. 249-265.

Jantsch, E. Technological Forecasting in Perspective, Report for the Organization for Economic Co-operation and Development (OECD), Paris, 1967.

Kerr, N. L.; MacCoun, R. J.; and Kramer, G. P. "Bias in Judgement: Comparing Individuals and Groups," Psychological Review (103:4), 1996, pp. 687-719.

Kindred, A. R. Data Systems andManagement: An Introduction to Systems Analysis andDesign ( $2^{\text {nd }}$ ed.), London: Prentice-Hall, 1980.

Land, F. “Adapting to Changing User Requirements," Information and Management (5), 1982, pp. $59-75$.

Lederer, A., and Nath, R. "Managing Organizational Issues in Information System Development," Journal of Systems Management (42:11), 1991, pp. 23-39

Lee, B. Basic Systems Analysis (2 ${ }^{\text {nd }}$ ed.), London: Hutchinson, 1984.

Lee, B. (Ed.). Introducing Systems Analysis and Design, Manchester, England: NCC Publications, 1979.

Lott, R. W. Basic Systems Analysis, London: Canfield Press, 1971.

Martin, C.; Vu, H.; Kellas, G.; and Metcalf, K. "Strength of Discourse Context as a Determinant of the Subordinate Bias Effect," The Quarterly Journal of Experimental Psychology (52A:4), 1999, pp. 813-839.

Mayer, R. E. Thinking, Problem Solving, Cognition ( $2^{\text {nd }}$ ed.), New York: W. H. Freeman and Company, 1996.

Mulligan, N. W. "The Effects of Perceptual Inference at Encoding on Organization and Order: Investigating the Roles of Item-Specific and Relational Information," Journal of Experimental Psychology (25:1), 1999, pp. 54-69.

NCC. From the White Heat of Technology to the Knowledge E-conomy, 1966-2001, National Computer Centre: Manchester, England: NCC Publications, 2001 (available online at http://www.ncc.co.uk/ aboutncc/pdfs/ncc351.pdf).

NCC. Introducing Systems Analysis and Design, Volume 1, National Computing Centre, Manchester, England: NCC Publications, 1978.

Obolensky, N. Practical Business Re-engineering: Tools and Techniques for Achieving Effective Change, London: Kogan Page, 1995.

Pinto, J., and Slevin, D. "Critical Success Factors in Successful Project Implementation," IEEE Transactions on Engineering Management (EM 34:1), 1987, pp. 22-27. 
Poole, M .S. "Do We Have Any Theories of Group Communication?," Communication Studies (41:3), 1990, pp. 237-247.

Puccio, G. "Creative Problem Solving Preferences: Their Identification and Implications," Creativity and Innovation Management (8:3), 1999, pp. 171-178.

Rosenhead, J. "Robustness Analysis: Keeping your Options Open," in J. Rosenhead (Ed.), Rational Analysis for a Problematic World: Problem Structuring Methods for Complexity, Uncertainly and Conflict, Chichester, England: John Wiley and Sons, 1992, pp. 193-218.

Rosenhead, J., and Mingers, J. (Eds.). Rational Analysis for a Problematic World Revisited: Problem Structuring Methods for Complexity and Conflict $\left(2^{\text {nd }}\right.$ ed.), Chichester, England: John Wiley and Sons, 2001.

Sauer, C. Why Information Systems Fail: A Case Study Approach, Henley, England: Alfred Waller, 1993.

Senn, J. A. Analysis and Design of Information Systems ( $2^{\text {nd }}$ ed.), New York: McGraw-Hill, 1989.

Sloman, S. A. "Categorical Inference Is Not a Tree: The Myth of Inheritance Hierarchies," Cognitive Psychology (35), 1998, pp. 1-33

Stanovich, K. E., and West, R. F. "Discrepancies between Normative and Descriptive Models of Decision-Making and the Understanding/Acceptance Principle," Cognitive Psychology (38), 1999, pp. 349-385.

Teigen, K. H. "The Language of Uncertainty,” Acta Psychologica (68), 1988, pp. 27-38.

Tversky, A., and Kahneman, D. "The Framing of Decision and the Rationality of Choice," Science (221), 1981, pp. 453-458.

Tversky, A., and Kahneman, D. "Judgement Under Uncertainty: Heuristics and Biases," Science (185), 1974, pp. 1124-1131.

Vesely, S. “A Time-Dependent Methodology for Fault Tree Evaluation," Nuclear Engineering and Design (13), 1970, pp. 337-360.

Vollmeyer, R.; Burns, B. D.; and Holyoak, K. J. "The Impact of Goal Specificity on Strategy Use and the Acquisition of Problem Structure," Cognitive Science (20), 1996, pp. 75-100.

Waddington, C. H. Tools for Thought, St. Albans, UK: Paladin, Frogmore, 1977.

Wertheimer, M. "Untersuchunngen zur lehre von der Gestalt," Psychologischo Forshung (4), 1923, pp. 301-350.

Wetherbe.J. C. Systems Analysis for Computer-Based Information Systems, St. Paul, MN: West Publishing Company, 1979.

Yourdon, E., and Constantine, T. Structure Design: Fundamentals of a Discipline of Computer Program and Systems Design, Englewood Cliffs, NJ: Prentice-Hall, 1979.

Yeates, D. An Introduction to Systems Analysis and Design, Milton Keynes, England: Open University Press, 1973.

\section{ABOUT THE AUTHORS}

Carl Adams is a principle lecturer in Information Systems and e-commerce at the University of Portsmouth, UK. His research interests include IS development practice, mobile applications and development, trust, electronic commerce, and cultural and social implications of technology. He can be contacted by e-mail at carl.adams@ port.ac.uk.

David Avison is Professor of Information Systems at ESSEC Business School, Paris, France after nine years at the School of Management at Southampton University for nine years. He is also Professor of Information Systems at Brunel University in England and visiting professor at University Technology, Sydney, Australia. He is joint editor of Blackwell Science's Information Systems Journal now in its $14^{\text {th }}$ volume. A past chair of WG 8.2, David is currently vice chair of IFIP Technical Committee 8 and represents France on that committee. 


\section{Appendix}

\begin{tabular}{|c|c|}
\hline \multicolumn{2}{|l|}{ (1) Brainstorming approaches } \\
\hline Affinity diagram & Bicheno (1994) \\
\hline Association/images technique & Couger, Higgins, and McIntyre (1993) \\
\hline Brainstorming & $\begin{array}{l}\text { Clark (1958), De Bono (1977), Waddington } \\
\text { (1977) }\end{array}$ \\
\hline Brainwriting—sharedenhancements variation & $\begin{array}{l}\text { Couger, Higgins, and McIntyre (1993), } \\
\text { Geschka(1996) }\end{array}$ \\
\hline Bug List & Couger, Higgins, and McIntyre (1993) \\
\hline Delphi & Carley (1980), Waddington (1977) \\
\hline Fagan Reviews & Fagan (1976) \\
\hline Five Ws and the $H$ & Couger, Higgins, and McIntyre (1993) \\
\hline Force field analysis & Couger, Higgins, and McIntyre (1993) \\
\hline Lateral thinking techniques & De Bono $(1969,1970,1977)$ \\
\hline Nominal group technique (NGT) & Couger, Higgins, and McIntyre (1993) \\
\hline $\begin{array}{l}\text { SIL_-suggested integration of problem ele- } \\
\text { ments }\end{array}$ & Couger, Higgins, and McIntyre (1993) \\
\hline Wildest idea & Couger, Higgins, and McIntyre (1993) \\
\hline \multicolumn{2}{|l|}{ (2) Relationship approaches } \\
\hline Analytic hierarchy process & Gajpal, Ganesh, and Rajendran (1994) \\
\hline Boundary examination & Couger, Higgins, and McIntyre (1993) \\
\hline Cognitive mapping & Eden (1992) \\
\hline Critical path analysis (CPA), method (CPM) & Jantsch (1967) \\
\hline Decision trees & Avison and Fitzgerald (2003) \\
\hline Fault tree analysis & Andrew and Moss (1993), Vesely (1970) \\
\hline $\begin{array}{l}\text { Influence diagrams, interrelationship dia- } \\
\text { grams }\end{array}$ & Bicheno (1994) \\
\hline McKinsey 7 S Framework & Obolensky(1995) \\
\hline Network techniques & Jantsch (1967) \\
\hline $\begin{array}{c}\text { Planning assistance through technical evalua- } \\
\text { tion of relevance numbers (PATTERN) }\end{array}$ & Jantsch (1967) \\
\hline $\begin{array}{l}\text { Precedence diagramming method (PDM) } \\
\text { network }\end{array}$ & Obolensky (1995) \\
\hline $\begin{array}{l}\text { Program evaluation and review technique } \\
\quad(\text { PERT) }\end{array}$ & Jantsch (1967) \\
\hline Reliability networks & Andrew and Moss (1993) \\
\hline Strategic choice & $\begin{array}{l}\text { Friend and Hickling (1997), Rosenhead } \\
\text { (1992) }\end{array}$ \\
\hline $\begin{array}{l}\text { Strategic options development and analysis } \\
\quad \text { (SODA) }\end{array}$ & Eden $(1992)$ \\
\hline Tree analysis & Andrew and Moss (1993) \\
\hline Value chain analysis & Obolensky (1995) \\
\hline \multicolumn{2}{|l|}{ (3) Scenario approaches } \\
\hline Future analysis & Land (1982) \\
\hline Robustness analysis & $\begin{array}{l}\text { Rosenhead (1992), Rosenhead and Mingers } \\
\text { (2001) }\end{array}$ \\
\hline Scenario planning/writing/analysis & Carley $(1980)$ \\
\hline
\end{tabular}




\begin{tabular}{|c|c|}
\hline \multicolumn{2}{|l|}{ (4) Reductionist approaches } \\
\hline Common causefailures (CCFs) & Andrew and Moss (1993) \\
\hline Hazard and operability studies (HAZOP) & Andrew and Moss (1993) \\
\hline $\begin{array}{l}\text { Hazards analysis and critical control points } \\
\text { (HACCP) }\end{array}$ & Camden (1987) \\
\hline Maintainability analysis & Andrew and Moss (1993) \\
\hline Morphological approaches & $\begin{array}{c}\text { Couger, Higgins, and McIntyre (1993), } \\
\text { Geschka (1996), Jantsch (1967), }\end{array}$ \\
\hline Preliminary hazard analysis & Andrews and Moss (1993) \\
\hline Risk assessment/engineering/management & $\begin{array}{l}\text { Andrew and Moss (1993), Beard (1969), } \\
\text { Chapman (1984, 1990), Grey (1995) }\end{array}$ \\
\hline $\begin{array}{l}\text { Synergistic contingency evaluation and review } \\
\text { technique (SCERT) }\end{array}$ & Chapman (1984) \\
\hline Systems failure method (SFM) & Fortune and Peters (1995) \\
\hline \multicolumn{2}{|l|}{ (5) Matrix approaches } \\
\hline Attribute association & Couger, Higgins, and McIntyre (1993) \\
\hline Bug list & Couger, Higgins, and McIntyre (1993) \\
\hline Critical success factors (CSF) & Flynn (1992), Pinto and Slevin (1987) \\
\hline Cross-impact matrices & Waddington (1977) \\
\hline Decision matrices & Jantsch (1967) \\
\hline Decomposable matrices & Couger, Higgins, and Mclntyre (1993) \\
\hline Dimensional analysis & Couger, Higgins, and Mclntyre (1993) \\
\hline External dependencies & Oblensky (1995) \\
\hline Failure Modes and Effect Analysis (FMEA) & $\begin{array}{l}\text { Andrew and Moss (1993), Bicheno (1994), } \\
\text { Fortune and Peters (1995) }\end{array}$ \\
\hline Five "Cs" and "Ps" & Obolensky (1995) \\
\hline Five whys & Bicheno (1994) \\
\hline Forcefield analysis & Couger, Higgins, and McIntyre (1993) \\
\hline Johari window of knowledge & Obolensky (1995) \\
\hline Markov chains, Markov analysis & Andrew and Moss (1993) \\
\hline Matrix techniques, matrix analysis & $\begin{array}{l}\text { Bicheno (1994), Geschka (1996), Jantsch } \\
\text { (1967) }\end{array}$ \\
\hline Opposition-support map & Obolensky (1995) \\
\hline Options matrix & Obolensky (1995) \\
\hline Rapid ranking & Andrew and Moss (1993) \\
\hline Requirements, needs andpriorities (RNP) & Batiste and Jung (1984) \\
\hline Shareholder value analysis (SVA) & Obolensky (1995) \\
\hline Stakeholder analysis & Obolensky (1995) \\
\hline $\begin{array}{l}\text { SWATanalysis (strengths, weaknesses, oppor- } \\
\text { tunities and threats) }\end{array}$ & Obolensky (1995) \\
\hline Value chain analysis & Obolensky (1995) \\
\hline Value engineering/management & Obolensky (1995) \\
\hline \multicolumn{2}{|l|}{ (6) Conflict approaches } \\
\hline Gaming, game theory & Jantsch (1967) \\
\hline Hypergames & Bennet, Cropper, and Huxham (1992) \\
\hline Metagames & Howard (1992) \\
\hline$R B O$ - rational bargaining overlaps & Obolensky (1995) \\
\hline Simulation & Andrew and Moss (1993), Carley (1980) \\
\hline Systems failure method (SFM) & Fortune and Peters (1995) \\
\hline
\end{tabular}

